\title{
Histopathological changes of some internal organs in broilers fed T-2 Toxin
}

\author{
Shereen K. K.
}

Coll.of Edu. /Unive.of Mosul

\begin{abstract}
Forty, one-day-old male broiler chicks (Ross 308), were randomly distributed at one day of age to 2 experimental groups consisting of 10 birds with two replicates for 35 days. Group 1 fed control diet with no T-2 toxin (negative control), while group 2 fed T-2 toxin contaminated diet at a rate of $4 \mathrm{ppm}$. Scarifying birds done at the end of the experiment, bursa of Fabricius, spleen, liver, kidney and intestine, were sectioned for microscopical examination. Results showed that T-2 toxin, was hepatotoxic, nephrotoxic, toxic to lymphatic tissue, haemopoetic tissue, and gastrointestinal tissues. And these organs are considered to be the target organs for $\mathrm{T}-2$ toxin which primarily affected during $\mathrm{T}-2$ toxicosis..
\end{abstract}

Key words: T-2 toxin, broilers, histopathology.

\section{Intruoduction}

Trichothecene mycotoxins are produced by common soil and plant fungi found worldwide, including Fusarium Myrothecium, Stachybolrys, Cephalosporium, Trichoderma, Trichothecium, Cylindrocarpon, Veriticimonosporium, and Phomopsis (1). Poultry are usually exposed to nonmacrocyclic trichothecenes, which includes type A trichothecenes (T-2 toxin, neosolanial, DAS, and others) and type B (nivalenol, DON, fusarenone-X, and others) . T-2 toxin occur in feedstuffs worldwide, including corn, wheat, barley, oats, rice, rye, sorghum. Safflower seed, mixed feed, and brewer's grains (2). Chickens with fusariotoxicosis (probable trichothecene mycotoxicosis) had reduced growth, severe depression, and bloody diarrhea (3).At necropsy, lesions were necrosis of oral mucosa. Reddening of the gastrointestinal mucosa, mottling of the liver. Gallbladder distention, atrophy of the spleen, and visceral hemorrhages. More recently in broilers, T-2 toxin produced by Fusarium tricinctum-eontaminated feed and litter reduced growth and caused skin lesions on the feet and legs, and ulceration and crusting of the oral mucosa (4). Another report found digestive and nervous signs, reduced growth. Rickets, abnormal feathering, pigmentation defects and hemorrhages. $\mathrm{T} \cdot 2$ toxin, detected at 1-4 mglkg in feed produced from crib-stored corn (5). Histopathology revealed degeneration of intestinal epithelium and acute tubular injury in the kidney. Experimental Disease Experimental trichothecene mycotoxicosis in poultry has required several approaches to reproduce fully the disease spectrum observed naturally: purified toxin administered either in solution or in the diet, and toxigenic fungal cultures (6). Collectively, these toxins cause feed refusal, impaired growth and reproductive capability; and whole-body pathology including caustic injury to skin and alimentary mucosa; radiomimetic injury to bone marrow, lymphoid tissues, gastrointestinal tract, and feathers; hepatosis; and thyroid alterations. Neurotoxicity of T-2 toxin and other trichothecenes is inconsistently reported as abnormal wing positioning, seizures, and loss of righting response (7); brain neurotransmitters are affected (8). The histopathology of acute oral intoxication by purified T-2 toxin or DAS was characterized by rapid necrosis and depletion of lymphoid and hematopoietic' tissues and then relatively rapid recovery (9). The liver had foci of hepatocyte necrosis and hemorrhage, necrosis and inflanunation of the gallbladder mucosa, 
and then mild proliferation of bile ductules. Transient shortening of villi followed necrosis of intestinal epithelium. Necrosis also occurs in the mucosa of the proventriculus and gizzardand in feather epithelium. Extended exposure to T-2 toxin and DAS and other scirpenol toxins caused reductions in body weight and skin pigmentation, anemia, and malformed (10). Lymphoid organs atrophied; the bone marrow became pale red or yellow; and the liver yellows Histopathology revealed

\section{Materials and methods}

This study was carried out on 40 oneday-old male broiler chicks (Ross 308), procured from commercial hatchery, during 2011 year. The study carried out in a private Poultry farm in Arbil. Birds were randomly distributed at one day old to 2 experimental groups each containing 10 birds with two replicates. They reared on deep litter system for 35 days. The temperature degree was recorded of approximately $35 \pm 2.0 \mathrm{C}^{\mathrm{O}}$ at the first day, then the temperature degree gradually decreased by $2.5 \mathrm{C}^{\circ}$ each week until the end of the experiment. All diets formulated to provide the nutrient requirements according (12). The ration based on yellow-corn soya bean contained $23.99 \%$ crude protein and $3188 \mathrm{Kcal}$ metabolizable energy. Offering Feeds and water were $a d$ libitum. Continuous lighting program (24hr) used during the completely experimental period. Production of purified crystalline T-2 toxin was by culturing Fusarium tricinctum 3299 according to the method reported by (13). The crystalline

\section{Results}

The microscopical histopathological lesions were present in all examines organs, i.e., in lymphoid tissues, alimentary tract, liver and, kidney.

\section{Bursa of Fabricius:}

T-2 mycotoxin causes pathomorphological alterations in bursa of Fabricius. These changes are characterized by hyperplasia , discontinuation or even necrosis in the bursal mucosa . Lack of corticomedullary differentiation, depletion and atrophy of cellular depletion of lymphoid and hematopoietic tissues and in the liver, vacuolar change in hcpatocytes and mild proliferation of bile ducts. In the thyroid gland, the follicles became small and had pale colloid. Clinical Pathology In broilers, T-2 toxin and DAS generally caused anemia associated with marked hematopoietic depletion in the bone marrow (11). The aim was to study the histopathological changes caused by feeding 4 ppm T-2 toxin to broilers.

toxin was calculated using Neogen ELISA kit (Neogen Corporation) with $\mathrm{XL}_{800}$ reader. The toxin containing maize was added to experimental diets, and mixed to homogeneity by means of a twin -shell blender. Checking the experimental ration to contain no detectable levels of aflatoxins, Ochratoxins, Zearalenone, and $\mathrm{T}-2$ toxin was by the method reported by (14). The experimental treatments were as follow: Group 1 has no toxin (negative control); Group 2 contains 4ppm T-2 toxin. Birds vaccinated against Newcastle disease and infectious bronchitis by spray method at one day of age, Newcastle disease at 8 days and infectious bursal disease at 14 days of age.Scarifying birds done at the end of the experiment, pieces of bursa of Fabricius, spleen, liver, intestine and kidney were put in $10 \%$ formalin, fixed in paraffin, and then sectioned at thickness of $5 \mu$ for microscopical examination. Staining sectioned organs Hematoxylin and eosin was used ( 15 ).

lymphoid tissue in the cortex and medulla with significantly reduction in the cortical area. Follicles showing lymphocytolysis with lymphoid depletion and necrosis in more than 50 per cent of cells, mild cyst formation. Other prominent findings were interfollicular odema and mild fibrosis (Fig.1\&2).

\section{Spleen}

Pathohistological examination of spleen showed Isolated lymphoid cell depletion and necrosis.There was a diffuse 
hyperaemia and haemorrhagic foci (Fig.3\&4).

\section{Liver}

Pathohistological examination of liver from broilers fed T-2 toxin contaminated feed, revealed cytoplasmic vacuolation in moderately swollen hepatocytes, periportal fibrosis, bile duct hyperplasia, periportal lymphocytic infiltration and mild degeneration with focal necrosis ( FIG.5\&6).

\section{Intestine}

Damage to the mucosa of the digestive tract of T-2-fed birds showed shortening, fusion of villi, degeneration and descquamation of enterocytes and goblet cell hyperplasia (Fig.7).

\section{Kidney}

Chickens fed T-2 toxin showed white and swollen kidneys. Kidney showed tubular epithelial degeneration and necrosis (Fig.8).

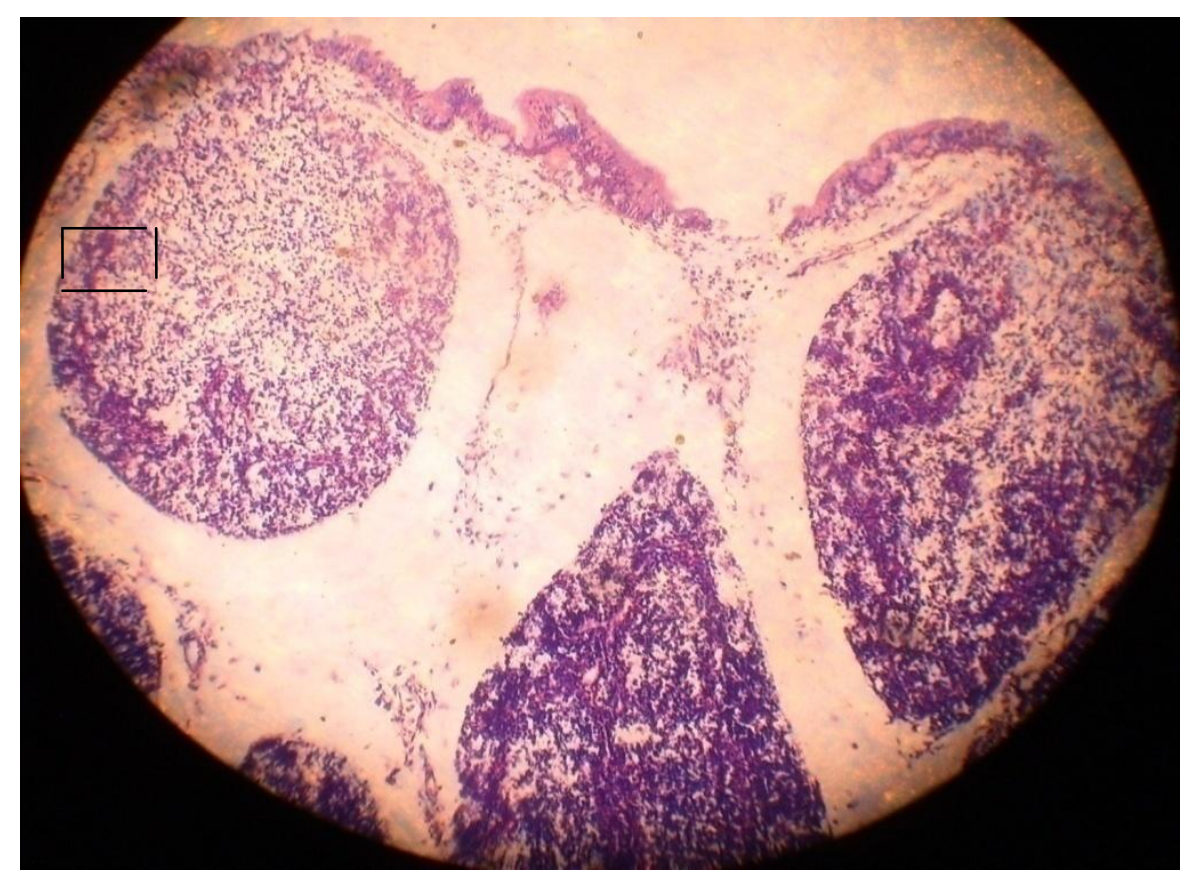

Figure 1: histopathological depletion and atrophy of lymphoid tissue in the cortex and medulla , lymphocytolysis. lymphoid necrosis and interfollicular odema and mild fibrosis in bursa of Fabricius of broilers fed T-2 toxin.(35X) 


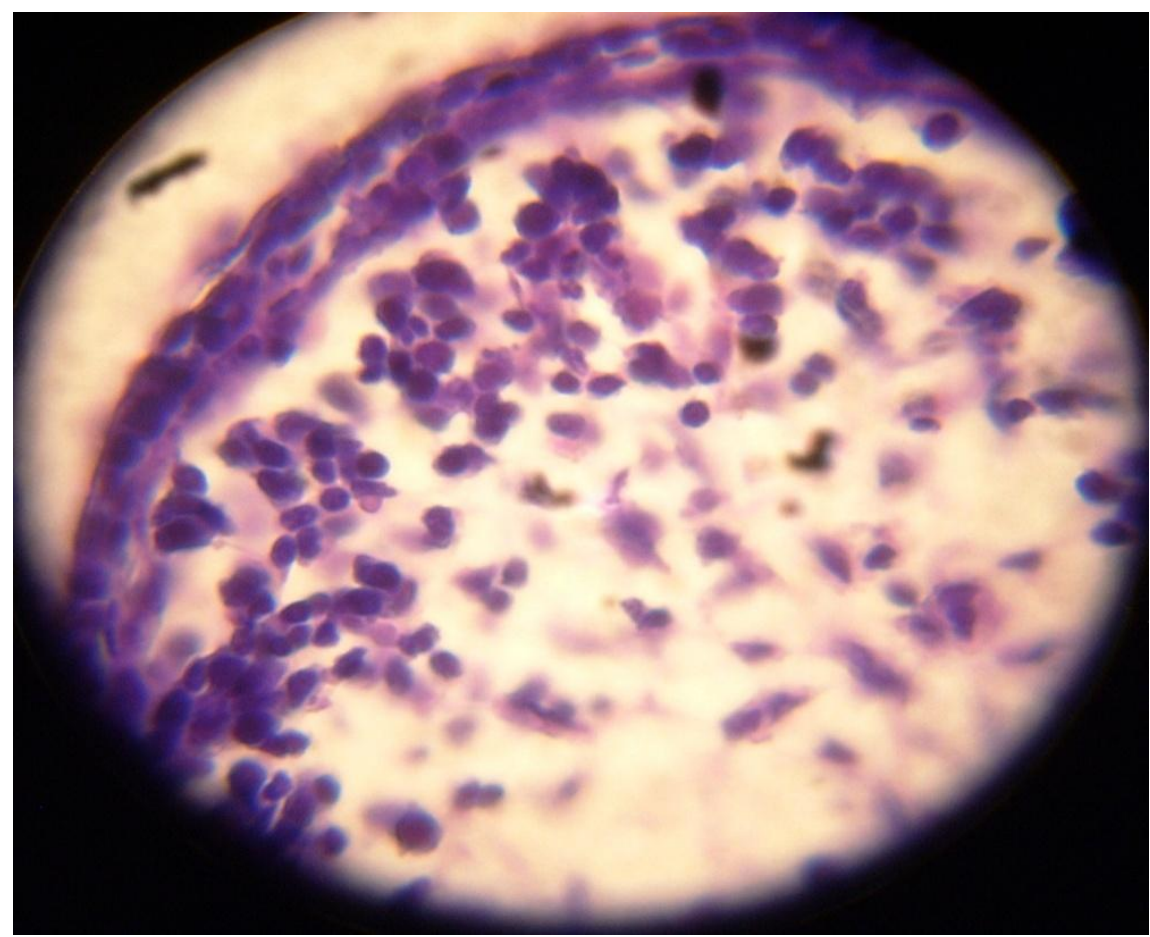

Figure 2: Magnification of figure 1 showing reduction in the cortical area, lymphocytolysis, and necrosis in more than 50 per cent of cells of medulla of bursa of Fabricius of broilers fed T-2 toxin. (200X)

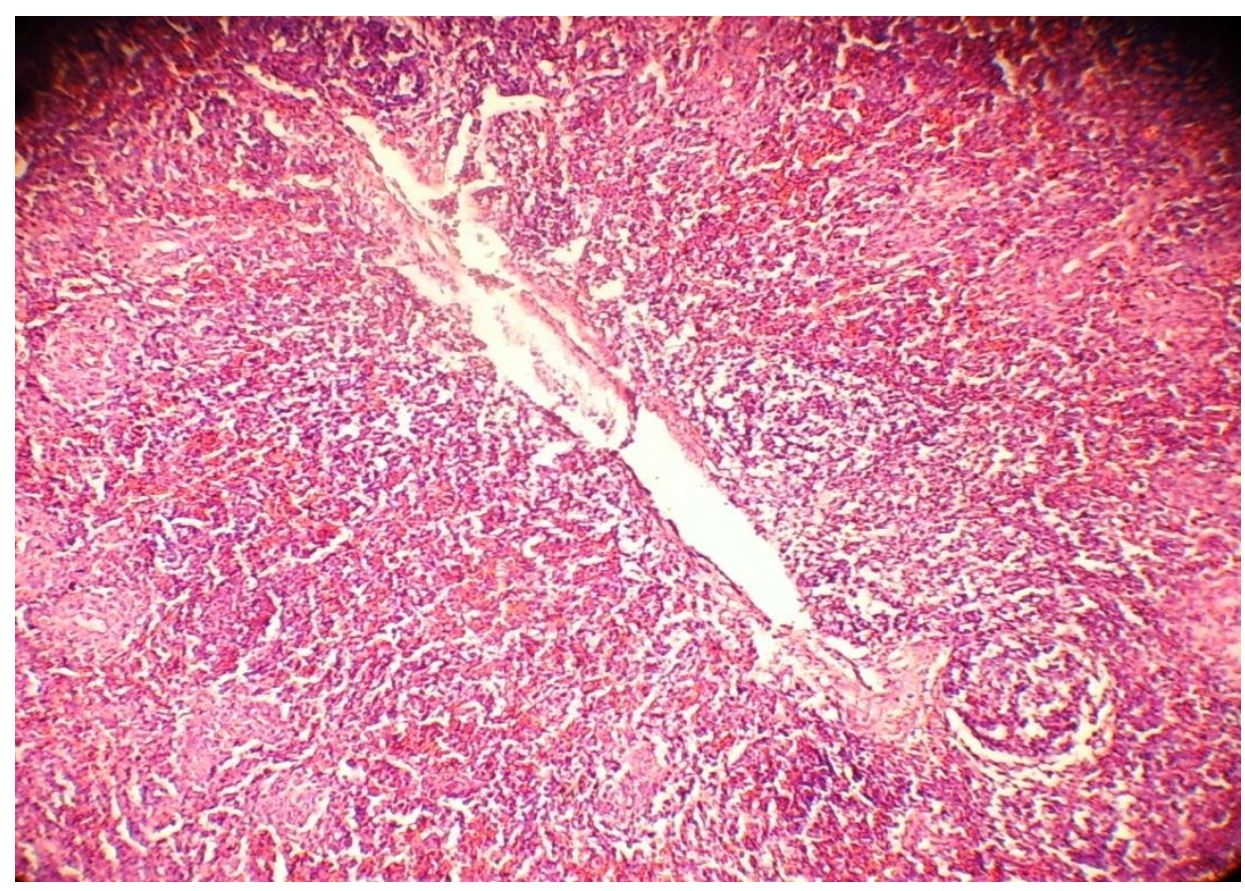

Figure 3:Pathohistological picture of spleen show isolated lymphoid cell depletion and necrosis in broilers fed T-2 toxin. $(65 \mathrm{X})$ 


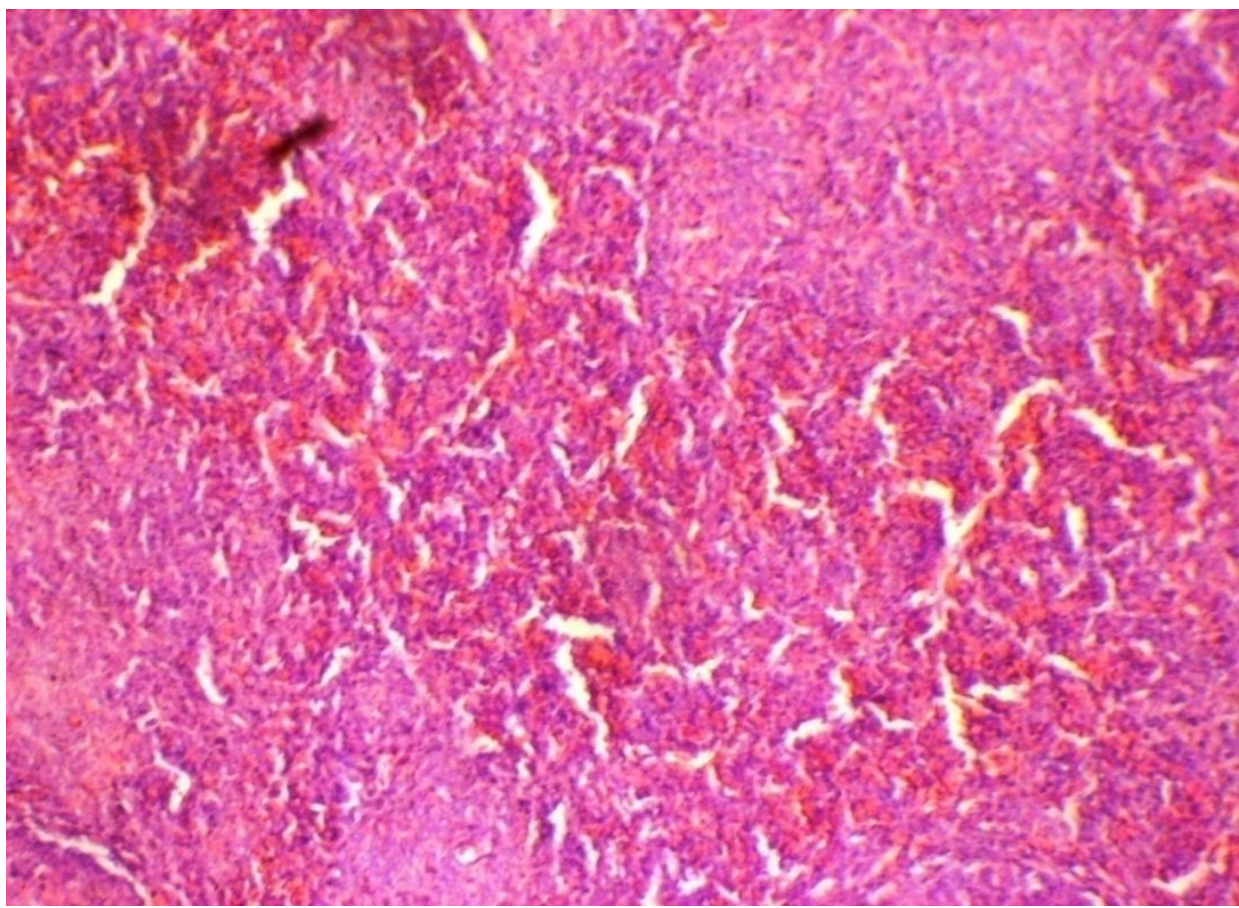

Figure 4: Pathohistological picture of spleen show diffuse hyperaemia and haemorrhagic foci in broilers fed T-2 toxin. $(200 \mathrm{X})$

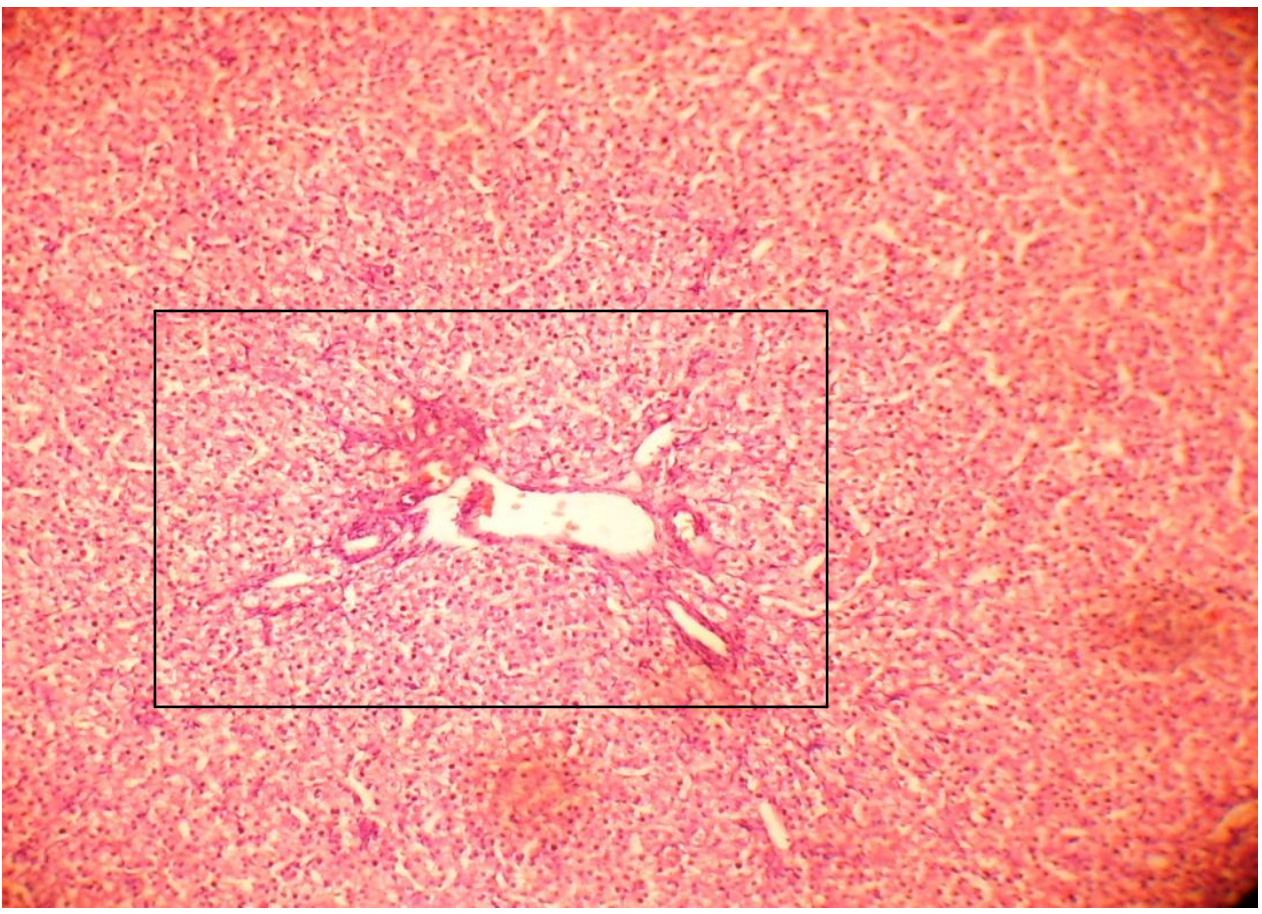

Figure 5:Pathohistological examination of liver from broilers fed T-2 toxin, revealed cytoplasmic vacuolation in moderately swollen hepatocytes.(145X) 


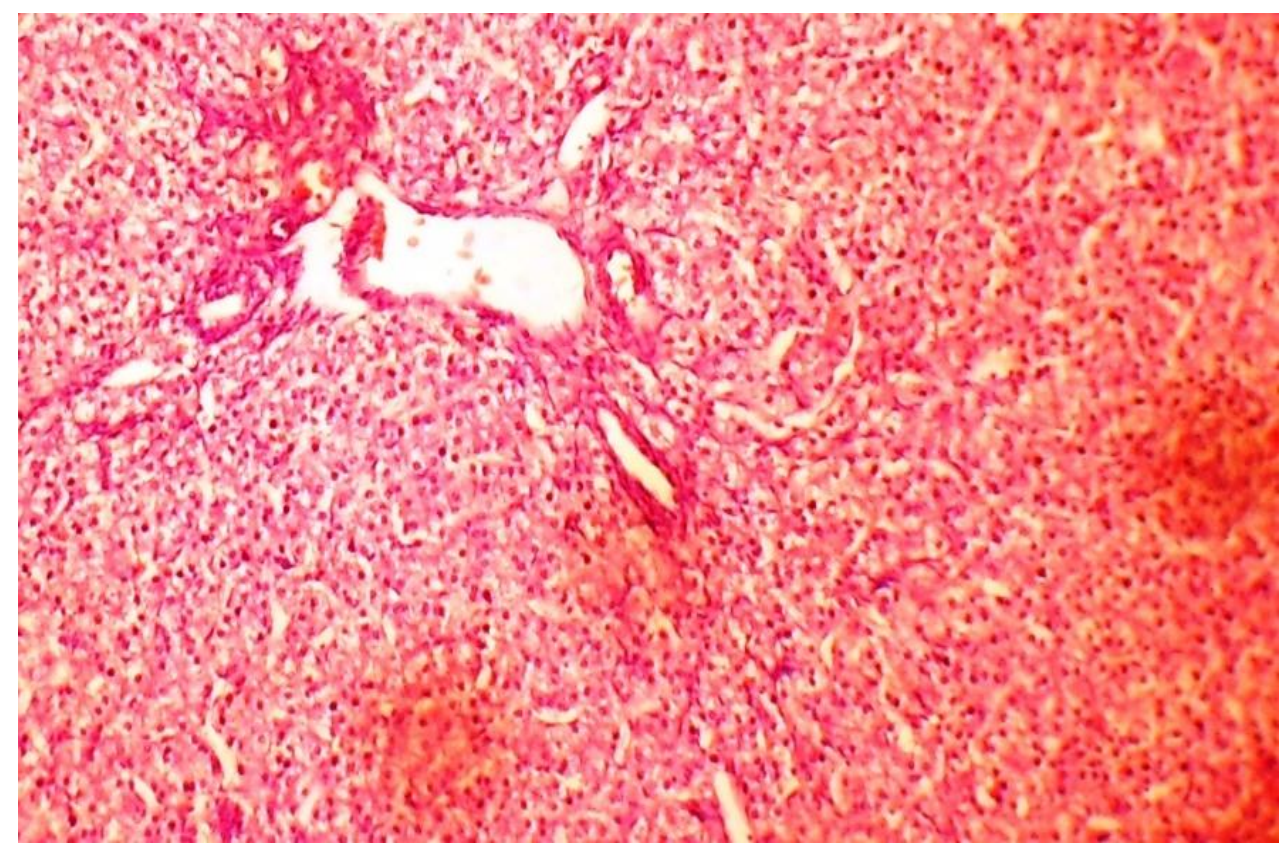

Figure 6: Magnification of figure 5 showing periportal fibrosis, bile duct hyperplasia, and hepatocytes vacculation in broilers fed T-2 toxin. (145X)

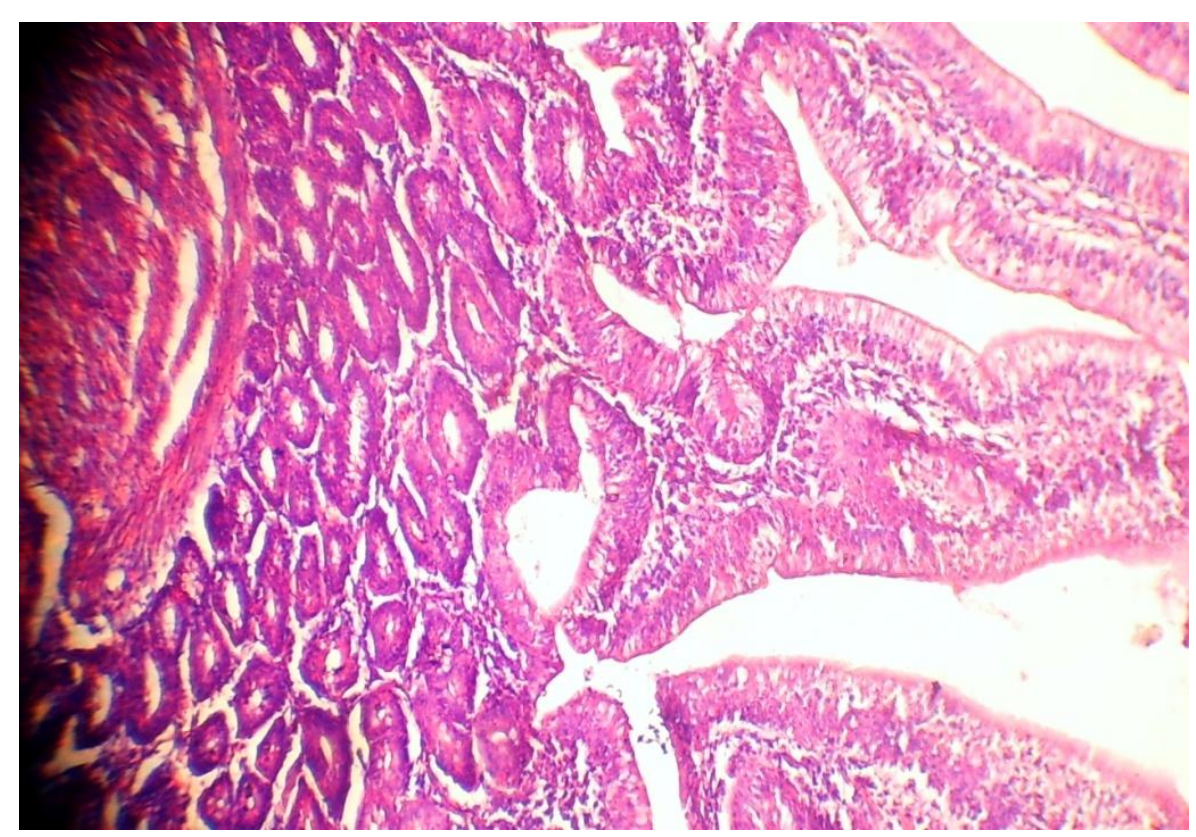

Figure 7: Pathohistological examinationof small intestine showing shortening, fusion of Villi, and goblet cell hyperplasia in broilers fed $\mathrm{T}-2$ toxin.(35X) 


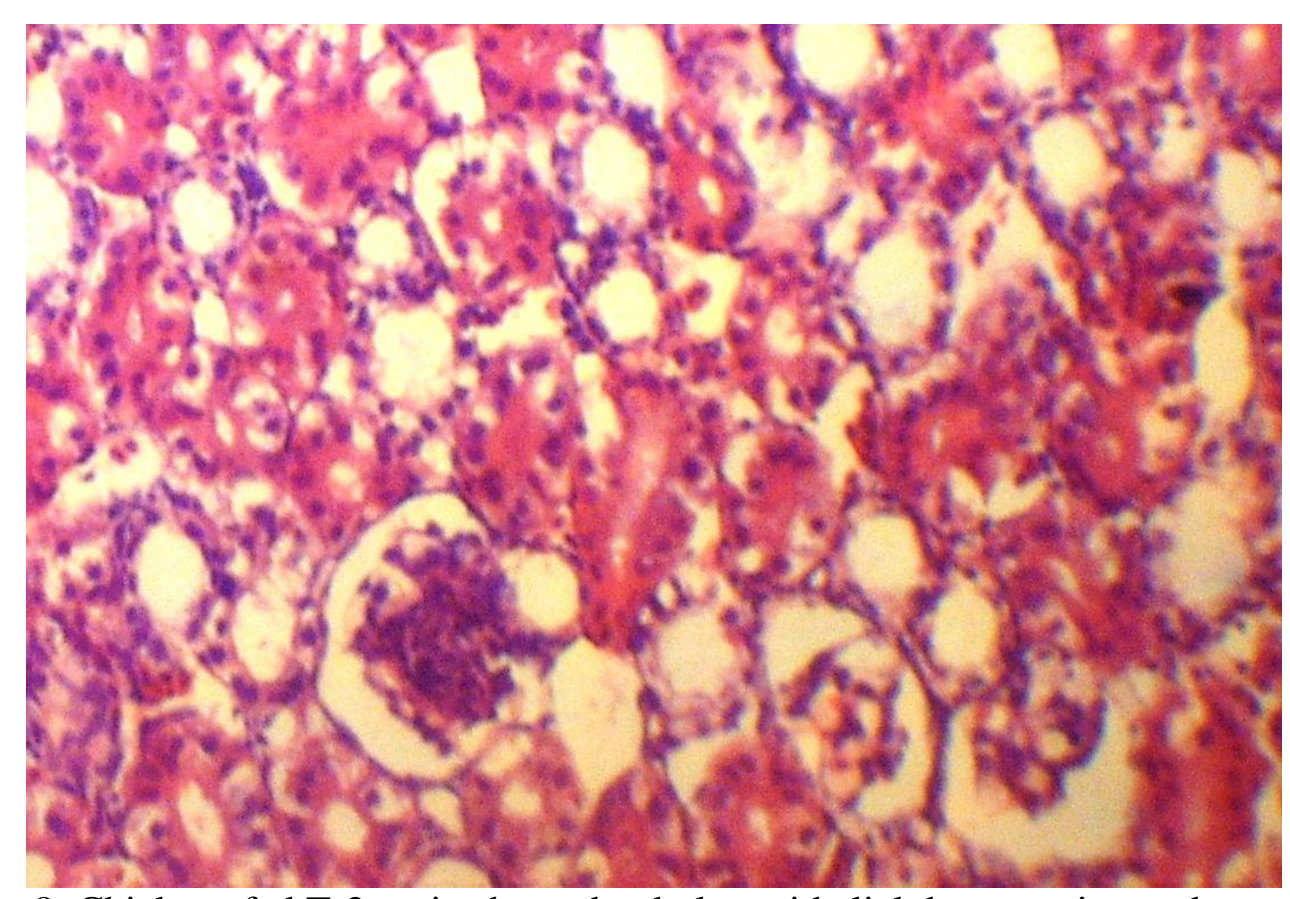

Figure 8: Chickens fed T-2 toxin showed tubular epithelial degeneration and necrosis of affected kidneys(165X)

\section{Discussion}

Trichothecenes, of which T-2 toxin, are hepatotoxins, nephrotoxins, lymphatic tissue, haemopoetic tissue, and gastrointestinal tissue mycotoxins. These tissues are the most sensitive to the action of trichothecenes (18). In our study, the effect of feeding broilers 4 ppm T-2 toxin on the histomophological feature of liver could be related to the morphological and functional effect of the toxin to liver membranes as referred by (19), since it is the main in vivo target organ for T-2 toxin effect. This toxin by its negative effect could induce inhibition of protein synthesis and reduce the activity of the enzymes necessary for the metabolism of toxic substances(20). These effects could lead to some extent to the focal disseminated liver necrosis (21). Periportal fibrosis, bile duct hyperplasia and periportal lymphocytic infiltration, which was evident in this study broiler chicks fed 4 ppm T-2 toxin, were coincide with(22).T-2 toxin was reported to induce damage to the mucosa of the mouth , gizzard tissue, intestinal digestive tract resulting in impairment of neutriant resorption (23). Our findings of villi fusion and shortening with goblet cell hyperplasia were in the line of other reports (24).Feeding T-2 toxin had lymphocyte necrosis with depletion of lymphocytes in the bursa of Fabricius and spleen, was also reported by (25), as well as atrophy of the lymphoid organs was in compitable with $(26,27,28)$. The interfollicular odema, mild fibrosis, lack of corticomedullary differentiation, medullary and lymphocytolysis observed here in the bursa of Fabricius of birds fed T-2 are correlated with the findings of (23). The reduced cortical area of bursal follicles with clear delimitation of the cortical and medullar regions were in line with (29). These effects of T-2 toxin on lymphoid tissues could be attributed to the damage to cell membrane, endoplasmic reticulum, mitochondria, nuclear membrane and cell apoptosis in the these tissues which were described by (21,30). Hyperaemic spleen with hemorrhagic foci noticed in our study was also referred by(31). This indicated the affection of humoral and cellular immunity in the toxin fed birds. The damage caused by these toxins to lymphoid organs in broiler chicken, may predispose to various 
infectious diseases. The feed and feedstuffs meant for poultry should be screened for the presence of T-2 toxin before feeding to prevent the occurrence of economic losses to the poultry farmers due to various disease outbreaks (32). In this study

\section{References}

1. Leeson, S., Diaz, G. Summers,1. D.. Poultry Metabolic Disorders and Mycotoxins. Guelph, Canada University Books, 1995; Pp:190326.

2. Yoshizawa, T. In: Smith, J. E. Henderson R. (eds.). Mycotoxins and Animal Foods. CRC Press: Boca Raton, FL, 1991;pp: 301324.

3. Kunnanov, I. A., Novacky, A.. In: Wyllie, T. A., Morehouse, L. G (eds.). Mycotoxic Fungi, Mycotoxins, and Mycotoxicoses: An Encyclopaedic Handbook. II. Marcel Dekker: New York, 1978; pp: 322-326.

4. Whitaker, T. B.. Detecting mycotoxins in agricultural commodities. $\mathrm{Mol}$ Biotechnol.2003; 23 :61-71.

5. Renault, L., M. Goujet, A. Monin, G. Boutin, M. Palisse Alamagny, A.. Suspected mycotoxicosis due to tricbothecenes in broiler fowl. BuliAcad Vet Fr. 1979;52:181188.

6. Joffe, A. Z.. Fusarium Species: Their Biology and Toxicology.New York John Wiley and Sons, 1986; pp: 345-384.

7. Hoerr, F. 1., Catlton, W. W., Tuile,1., Vesonder, R. F., Rohwedder, W. K.Szigeti, G.. Experimental trichothecene mycotoxicosis produced in broiler chickens by Fusarium sporotrichiella V3r. spororrichiQides. Avian Patholll.1982 ; pp: 385-495.

8. Swamy, H. v., Smith, T. K., MacDonald, E. J.. Effects of feeding blends ofgrains naturally contaminated with Fusarium mycotoxins on brain regional ,broilers fed 4 ppm T-2 toxin exhibited white and swollen kidneys and had necrosis of renal tubular epithelium, changes similar to those reported by $(33,34)$. neurochemistry of starter pigs and broiler chickens. J Anim Sci. 2004; 82:2131-2139.

9. Hoerr, F. 1., Carlton, W. W., Vagen, B.. Mycotoxicosis caused by a single dose ofT-2 toxin or diacetoxyscirpenol in broiler chickens. Vel. Patho.1981;18:652664.

10. Parlchurst, C. R., Hamilton, P. B., Adcrnoyero, A. A..Abnormal feathering ofchicks caused by scirpenol mycotoxins differing in degree of acetylation. Pouit Sci.1992; 71 :833-831.

11. Pandc, V V, Kurkure, N. V., Bhandarkar, A. G.. Effect of T-2 toxin on growth, performance and hacmatobiochemical alterations in broilers. India" J Exp Bioi. 2006; 44:86-88.

12. NRC, "Nutrient Requirements of Poultry". 8th Revised Ed. National Academy Press, Washington, D. C. (1994).

13. Coker, R. D., Jones, B.D., Nagler, M.J., Gilman, G.A., Wallbridge, A.G., Panigrahi, S. Mycotoxin training manual, tropical products institute, London. 1984

14. Bancroft, J.D.; Stevens, A. Theory and Practice of Histological Techniques, 4th edn, Churchill Livingstone, London. 1996

15. B a i 1 e y, R. H., Ku b e n a, L. F., H a r v e y, R. B., B u c k le y, S. A., R o t $\mathrm{t}$ i n $\mathrm{g}$-h a u s, G. EEfficacy of various inorganic sorbents to reduce the toxicity of aflatoxin and T-2 toxin in broiler chickens, Poult Sci, 1998 ; 77: 1623-1630.

16. K u b e n a, L. F., H a r v e y, R. B., B a i 1 e y, R. H., B u c k 1 e y, S. A., R 
o t $\mathrm{t}$ i n $\mathrm{g}$-h a u s, G. E. Effects of a Hydrated Sodium Calcium Aluminosilicate (T-Bind ${ }^{\mathrm{TM}}$ ) on mycotoxicosis in young broiler chickens, Poultry Science, 1998; 77: 1502-1509.

17. Kalantari, H., Moosavi, M. Rreview on $\mathrm{t}-2$ toxin. Jundishapur Journal of Pharmaceutical Natural Products 2010; 5: 26-38

18. Tremel, H., Scenic, L. Effects of T-2 toxin, a trichothecene, in suspensions of isolated rat hepatocytes. Arch. Pharmacol. 1984; 325:29-34

19. Karppanen, A., Rizzo, L., Berg, S., Bostrom, H. Investigation on trichothecene-stimulated lipid peroxidation and toxic effects of trichothecenes in animals. Acta Veterinaria Scandinavica. 1989; 30: 391-399.

20. Frederic, J. H., William, W. C., Boris, Y., Abraham, Z. J. Mycotoxicosis caused by either T2 toxin or diacetoxyscirpenol in the diet of broiler chickens.Fund Appl Toxicol.1982;. 2:121-124.

21. Paramanandham, K., Subbiah V., Chidambaram B., Bhakatavatsalam M. Pathology of chlorpyriphos and T-2 toxin on broiler chicken Veterinarski Arhiv. 2007; 77 : 4757.

22. Kamal A.P. Individual and combined effects of cyclopiazonic acid and T-2 toxin in broiler chicken. Thesis. Madras Veterinary College, Tamilnadu Veterinary and Animal Sciences University, Chennai, India. (2003).

23. World Health Organization (WHO). Evaluation of certain mycotoxins in food. WHO Techn Rep Ser 906. Geneva: WHO; 2002.

24. Hurley, D. J., Neiger, R. D., Higgins, K. F., Rottinghaus, G. E., Stahr, H. Short-tenn exposure to subacute doses of aflatoxininduced depressed mitogen responses in young mallard ducks. Avian Dis. 1999; 43:649-655.

25. Neiger, R. D., Johnson, T. 1., Hurley, D. 1., Higgins, K. F., Rottinghaus, G. E., Stahr, H.. The short-term effect of low concentrations of dietary aflatoxin and T-2 toxin on mallard ducklings.Avian Dis. 1994;38:738-743.

26. F a z e k a s, B., H a j d u, E., T a n y i, J. Effect of Myco-AD on experimental T-2 toxicosis in broiler chickens, Australian Mycotoxin Newsletter, 2000 ; 11,: 10.

27. P. Krishnamoorthy1, S. Vairamuthu2, C. Balachandran2 and B. Muralimanohar3 Pathology of Lymphoid Organs in Chlorpyriphos and T-2 Toxin Fed Broiler Chicken. Int J Poul Sci. 2007;6: 71-76.

28. Muniz, E.C..,Fascina, V.B.., Pires, P.P., Carrijo, A.S., Guimarães ,E.B. Histomorphology of bursa of Fabricius: effects of stock densities on commercial broilers. Revista Brasileira de Ciência Avícola 2006; 8:

29. Pande, V., Kurkure, N., Bhandarka,r A. , Kalorey, D., Nagamallewshwari, Y. Histopathological and electron microscopic changes in $\mathrm{T}-2$ toxicosis in broiler chicks. Indian $\mathrm{J}$ Vet Pathol. 2011;35, 21- 26.

30. V e s n a, M. J ., A l e k s a n d r a, S. B o å a rov - S t a n å i ã. ,R a d m i 1 a, D. R ., S n e ÿ a n a, B. Đ .,D u b r a v k o, R. B ., Mi 1 o š, P. S . Basic mechanisms of the cellular alterations in $\mathrm{t}-2$ toxin poisoning: influence on the choice and result of the therapy. Proc. Nat. Sci.2007; 113, 45-53

31. Krishnamoorthy, P., Vairamuthu, S., Balachandran, C., Dhinakar raj, G., M urali manohar, B. Immunopathology of chlorpyriphos and T-2 toxin in broiler chicken. J. Immunol. Immunopathol. 2005; 7: 65-68. 
32. Malik, G., Dhahiya, J. P., . Sandeep, G., Mishra, S. K. Clinicopathological studies on chlorpyriphos intoxication in broiler chicken. Proceedings of 19th Annual Conference of Indian.Association of Veterinary Pathologists. 26-28 September. Palampur, India. 2002: pp. 124 produced in broiler chickens bymultiple doses of either $\mathrm{t}-2$ toxin or diacetoxyscirpenol. Avian Pathol, 1982; 11: 369-383.

34. Wyatt, R. D., Harris, 1. R., Hamilton, P. B., , Burmeister, H. R.. Possible outbreaks of fusariotoxicosis in avians. Avian Dis.1972;16:11231130

33. Hoerr, F.J., Carlton, W.W., Yagen, B.

JOFFE, A.Z. Mycotoxicosis

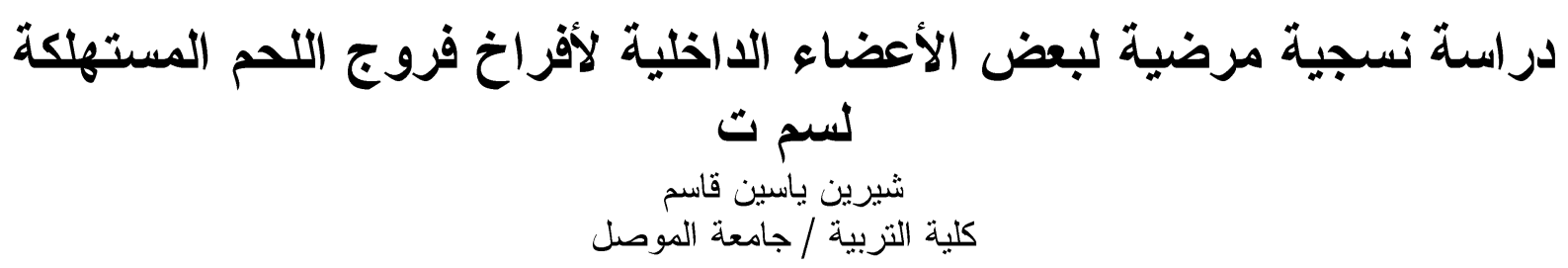

الخلاصة

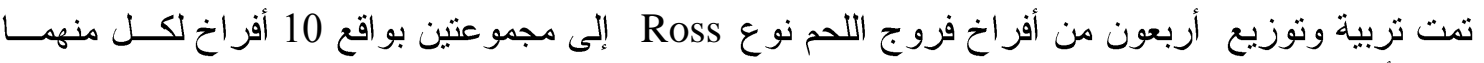

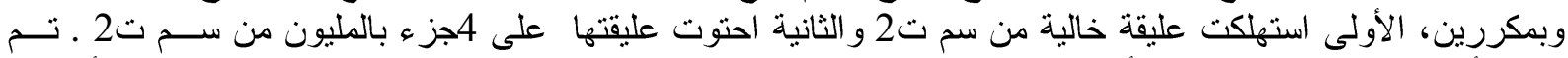

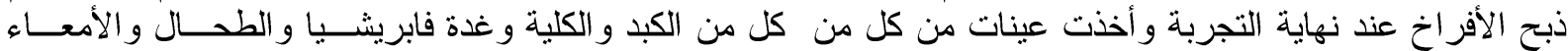

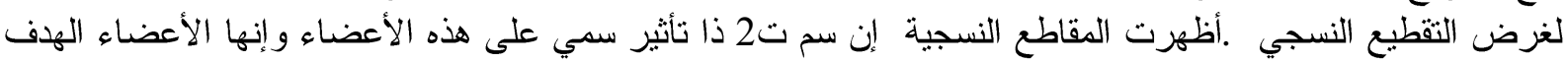

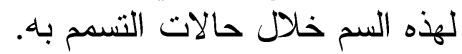
الكلمات المفتاحية: سم ت 2 ، أفر الخ فروج اللهم، التقطيع النسجي 